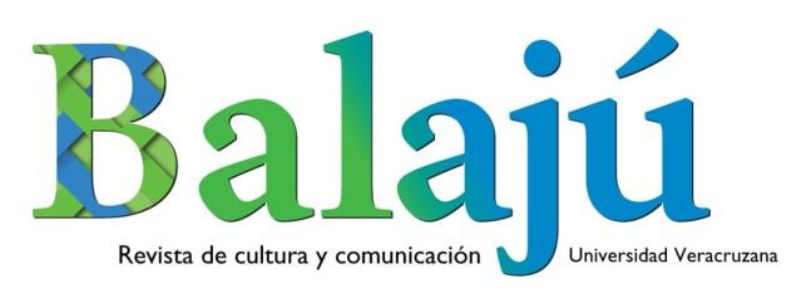

\title{
ISSN2448-4954
}

No. 11, Año 6

Agosto-Diciembre 2019

https://doi.org/10.25009/blj.voi11.2587

\section{La naturaleza domesticada como atributo del personaje en el retrato novohispano}

Domesticated Nature as an Attribute of the Person in New Spain Portraiture

\section{Beatriz Bastarrica Mora ${ }^{1}$ \\ https://orcid.org/0000-0001-9994-982}

RESUMEN: El género pictórico del retrato en general y el retrato novohispano en particular constituyen una fuente inagotable de información para la historia de las representaciones. Todos sus niveles de lectura ofrecen datos diversos sobre los personajes retratados: sus vidas y el contexto político, social y económico en el que estas se desarrollaron. Los retratos pintados en Nueva España durante el siglo XVIII, abundantes y de incalculable valor estético, operan a partir de una particular sincronía entre esta dimensión y otra, la de construcción de la persona como miembro de una sociedad compleja; y lo hacen por medio de estrategias narrativas como, por ejemplo, el uso de elementos propios de otros géneros pictóricos que, con su presencia, abonan a sus objetivos. En estas páginas se

${ }^{1}$ Universidad de Guadalajara, México. Correo electrónico: beatrizbastarricamora@gmail.com

Fecha de recepción: 07/12/2019. Aceptado: 07/05/2020 
analiza quizás el más notorio de estos géneros dentro del género: el paisaje, empleado en el retrato como naturaleza domesticada.

PALABRAS CLAVE: Retrato, Nueva España, paisaje, indumentaria, jardín.

\begin{abstract}
The portrait as a pictorial genre and the portraiture of New Spain in particular constitute an inexhaustible source of information for the history of representation. Read at multiple levels, portraits offer diverse data about the people they portray: their lives, and the political, social and economic context in which these were lived. Portraits painted in New Spain during the eighteenth century, abundant and rich in aesthetic value, operate from a particular synchrony between this dimension and another: the construction of the person as a member of a complex society, by means of narrative strategies such as the use of elements from other pictorial genres, whose presence contributes to the work's objectives. This article analyzes landscape as "domesticated nature," perhaps the most notorious of these genres within the genre.
\end{abstract}

KEYWORDS: Portrait, New Spain, landscape, attire, garden. 


\section{La naturaleza domesticada como atributo del personaje en el retrato novohispano}

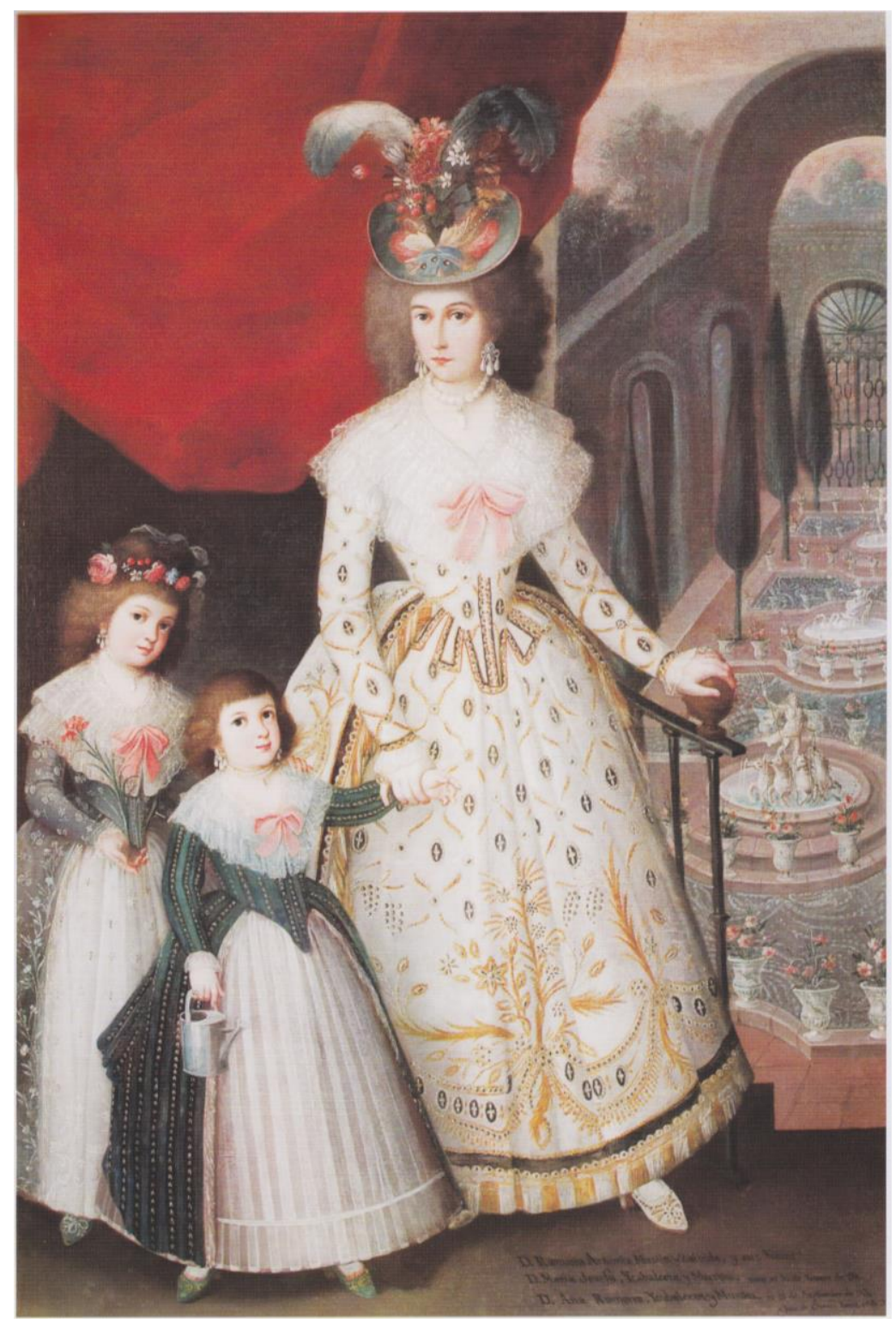

Figura 1. Juan de Sáenz, retrato de la señora Ramona Antonia Musitu y ZalvideGoitia y sus dos hijas, 1793. Óleo sobre tela, 200 x $140 \mathrm{~cm}$. Colección de Viviana Corcuera. 


\section{Retratadas para la posteridad}

Observemos con detenimiento a esta mujer y a sus dos hijas (figura 1). O, mejor dicho, observemos el retrato pictórico de Ramona Antonia Musitu y Zalvide-Goitia y sus hijas mayores: Ana Ramona Icazbalceta Musitu y María Josefa Blasa Magdalena Icazbalceta Musitu. Ramona Antonia -nacida en 1767 en Escoriaza, Guipuzcoa, casada con Nicolás Gorgonio Icazbalceta Herriarte en 1788, y muerta, probablemente en labores de parto, a la prematura edad de 34 años (Sanchiz, Gayol y AMGH, s.f.), ya afincada en Nueva España- nos mira atentamente desde su retrato, un óleo sobre lienzo de $200 \mathrm{~cm}$ de alto por $140 \mathrm{~cm}$ de ancho, pintado en 1793 por Juan Sáenz (Pérez y Quezada, 2009: 197). Ramona y sus hijas aparecen representadas de cuerpo entero, de pie y mirándonos en tres cuartos en el momento en que, aparentemente, se dirigen a un jardín, el cual vemos a sus espaldas. Vestidas de punta en blanco, con ropas a la última moda francesa y elaboradas con tejidos exóticos, dan la impresión de que las hemos sorprendido mientras se disponían a cuidar de dicho jardín -aunque sus vestidos, pelucas y tocados no se antojan, por lo pulcros y ostentosos, como los más adecuados para dicha actividad, físicamente exigente.

Entre las figuras y el jardín, un cortinaje rojo separa el interior del exterior, lo privado de lo público. Lo que está ante nuestros ojos es un retrato novohispano en todo su esplendor, con sus características propias y heredadas: digno ejemplo de determinados modelos de representación mental y física- de esas maneras de pensar que se dieron específicamente en Nueva España, tal y como autores como Alfonso Alfaro, Leonor Cortina o Tomás Pérez Vejo han descrito con detalle en numerosas investigaciones (Artes de México, 1994; Pérez y Quesada, 2009; Martínez y Servín, 2000). 


\section{El retrato novohispano, una máquina de significar}

El retrato pictórico, como género, puede considerarse un dispositivo de comunicación que, analizado de manera multidisciplinar, ayudaría a la descripción y el análisis cabales de tiempos, espacios y sociedades concretos. En la Nueva España del siglo XVIII, esta afirmación se vuelve particularmente importante, ya que los retratos combinan la función primaria de representar la fachada personal ${ }^{2}$ del retratado con la no menos importante de insertar al retratado en su grupo social.

Retratos como el de Ramona con sus hijas, de producción abundante en el periodo mencionado, ${ }^{3}$ reflejan la idiosincrasia novohispana imperante en cuanto al género pictórico. Esta se concreta en aspectos muy específicos e identificables; por ejemplo, el realismo sin concesiones del que hacen uso los artistas en la representación de los rasgos faciales de los retratados (Cortina, 1994: 44), aunque siempre respetando la concepción del retrato como la representación de la máscara (social) y no de la persona (individuo único, con su mundo íntimo) (Pérez y Quezada, 2009: 19). Lograr el parecido resultaba innegociable a la hora de pintar un retrato, tal como normarían por escrito autores contemporáneos esta pintura, o un poco posteriores, como Antonio Palomino -en su Museo pictórico y escala óptica, de 1795- o Francisco Pacheco. Este objetivo era perseguido por el

${ }^{2}$ Erving Goffman (1997: 35) define la fachada personal como el conjunto de las "insignias del cargo o rango, el vestido, el sexo, la edad y las características raciales, el tamaño y el aspecto, el porte, las pautas de lenguaje, las expresiones faciales, los gestos corporales y otras características semejantes" que una persona acumula y ordena, en la medida de sus posibilidades, para presentarse ante los demás. Este concepto se erige como una herramienta de análisis poderosa, al articular desde la significación, como un conjunto, todos y cada uno de los elementos que un observador atento -en este caso nosotros, investigadores en ciencias sociales- puede percibir en su interlocutor.

3 De hecho, la cantidad per cápita de retratos que se producen en el XVIII novohispano supera con creces la media de la producción en el resto del mundo en la época (Pérez y Quezada, 2009: 15). 
pintor generalmente sin idealizar o sin tratar, incluso, con amabilidad estética a sus clientes (Núñez, 2016: 21). Estos suelen aparecer representados con gestos faciales rígidos y posando en posturas que se repiten de uno a otro retrato (Cortina, 1994: 45), a veces incluso dentro de una misma pintura. También la fachada personal -integrada entre otros elementos por la ropa, las joyas y los peinados- será objeto de profundo escrutinio y de férrea reproducción pictórica, como apoyo estético a lo anterior pero, sobre todo, como una estrategia discursiva -reflejo exacto de lo que sucede en el mundo real-para construir y consolidar el estatus social del cliente.

Los retratos novohispanos -que, en palabras de Alfonso Alfaro, parecen habitar un tiempo estilístico e ideológico diferente al de sus contemporáneos europeos (Pérez y Quezada, 2009: 18)- fueron una forma frecuente de inversión pecuniaria para la adquisición de capital social y simbólico por parte de las élites tanto aristocráticas como burguesas. Es decir, fueron una de las herramientas estratégicas que estas utilizaron habitualmente para que los señores y señoras de Nueva España pudieran llegar a obtener un "lugar encumbrado en una jerarquía agonizante", y así reforzar "un proyecto personal y familiar sólidamente anclado en el siglo XVII: patrimonial, aristocrático" (Alfaro, 1994: 13).

Lo que yo propongo en las siguientes páginas -y es esta una proposición con raíces breves, germinales, pues esta investigación está aún en sus inicios- es que, al analizar este tipo de retratos, realicemos un salto conceptual intergéneros con el fin de añadir capas de significantes y significados a dicho análisis, con el objetivo de complicar y, con suerte, matizar y aclarar los resultados de nuestras pesquisas. Quiero proponer que, partiendo de una necesaria flexibilidad historiográfica, busquemos un género dentro de otro género, en este caso el paisaje dentro del retrato, y 
veamos entonces qué sucede con tales retratos en términos de representación.

\section{El paisaje como categoría conceptual y como género pictórico}

La definición que el Diccionario de la Real Academia Española ofrece del término "paisaje" ya adelanta parte del meollo de nuestra propuesta: que el paisaje no es un elemento intrínsecamente natural -o no es solo eso-. Que el paisaje es construcción. Dice la Real Academia acerca del término: que se refiere a "la parte de un territorio que puede ser observada desde un determinado lugar", a un "espacio natural admirable por su aspecto artístico" y, simétricamente, a "una pintura o dibujo que representa un paisaje (espacio natural admirable)". ${ }^{4} \mathrm{El}$ paisaje, como han planteado Maderuelo, Clark o Serraller, 5 es la construcción y reconstrucción que el ser humano hace de la naturaleza en el mundo físico, en su mente y en el arte, y esta construcción en muchas ocasiones encierra cierto nivel de domesticación de dicha naturaleza y de sus elementos constitutivos; el jardín es un ejemplo extremo de esta domesticación. El paisaje es, como consecuencia, una representación y, como toda representación, está cargada de subjetividad y de significado.

María Teresa Rodríguez Bote (2014: 373) abunda en esto al afirmar que "el paisaje refleja una actitud hacia la naturaleza, por lo que nunca habrá un paisaje neutro u objetivo”. En el arte flamenco y en el alemán, el paisaje adquiere autonomía iconográfica a partir del siglo XVI, apareciendo

4 https://dle.rae.es/paisaje,consulta del 28 de abril de 2020.

5 Javier Maderuelo coordina una magnífica serie de volúmenes sobre la cuestión del paisaje -entre ellos, Paisaje y arte (Madrid: Abada Editores, 2007)- en los que pueden escucharse las imprescindibles voces de autoridades en la materia como Kenneth Clark o Francisco Calvo Serraller. 
desde luego en culturas que, en palabras de Berque, reúnan cuatro requisitos fundamentales:

1. Una o más unidades léxicas que designen el concepto

2. Alguna manifestación literaria, ya sea oral o escrita, en la que se aluda explícitamente al paisaje

3. Representaciones pictóricas de paisajes

4. Jardines cultivados para el placer (Berque, en Rodríguez, 2014: 375).

\section{El paisaje novohispano: los biombos}

Algunos de los mejores ejemplos de paisaje pintado en el siglo XVIII novohispano los encontraremos en las decoraciones de los biombos también llamados en la época biogos, beobos y biobos ${ }^{6}{ }^{6}$ que se usaron en los hogares de la élite y de la burguesía del momento con diversos fines y ubicaciones: separar el espacio del estrado, femenino, del resto de la sala y de la casa; en las recámaras, para lograr espacios más íntimos; y, finalmente, también en otros lugares del hogar donde, según nos dice Gustavo Curiel (1999: 19), "el protocolo social era menos severo". Los biombos novohispanos llegaban de China y de Japón en la Nao de China, y fueron durante siglos objetos apreciadísimos; en ellos pronto comenzaron a pintarse, ya en suelo americano, motivos de la tierra, con personalidad propia: escenas de historia y de vida diaria, temas literarios, asuntos mitológicos, temas cortesanos, enseñanzas morales, protocolos de la vida

${ }^{6} \mathrm{Al}$ respecto de la historia del biombo en Nueva España, es de obligada lectura el catálogo homónimo de la exposición Viento detenido, mitologías e historias en el arte del biombo, publicado por la Asociación Carso y el Museo Soumaya en 1999. 
de la élite y, sí, vistas urbanas y escenas geográficas; es decir, algunos tipos de paisaje (Curiel, 1999: 20).

En orden cronológico inverso podemos señalar, como buenos ejemplos de lo dicho, el biombo - de 1780 y con cinco hojas- al que se ha titulado Vista de México (figura 2); el Grand Tour, que es un poco anterior (figura 3); y el más antiguo de los tres, una maravillosa representación de aves y de plantas de finales del siglo XVII (figura 4). 7 Como puede observarse, en los tres el estilo pictórico varía, así como las intenciones de representación de la naturaleza domesticada ${ }^{8}$ o paisaje.

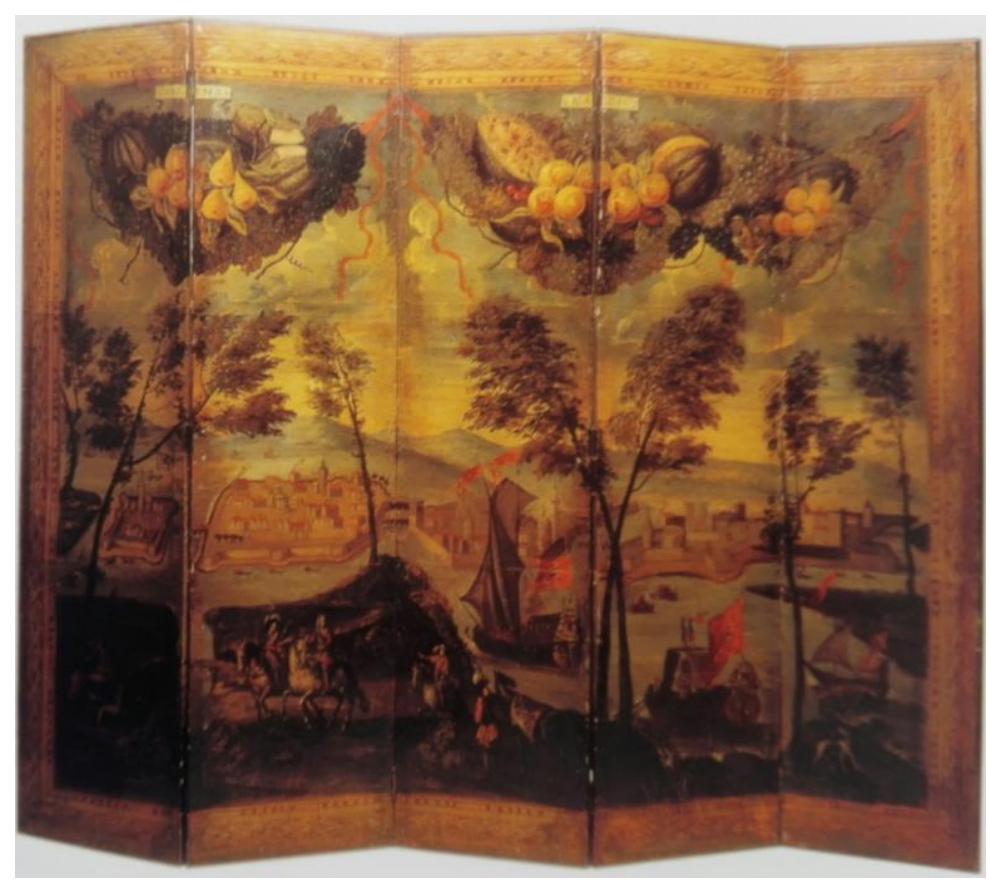

Figura 2. Vista de México, Escuela española, ca. 1780. Biombo de cinco hojas, óleo sobre lienzo, $2.12 \times 3.36 \mathrm{~m}$.

7 Estos ejemplos están incluidos en el catálogo ya citado de la exposición Viento detenido.

${ }^{8}$ Empleo esta expresión para referirme al conjunto de elementos naturales -casi siempre vegetales- que, estilizados, simplificados y/o idealizados, aparecen representados en cuadros, textiles y otros productos visuales dieciochescos, en forma de paisajes, naturalezas muertas o estampados decorativos. 


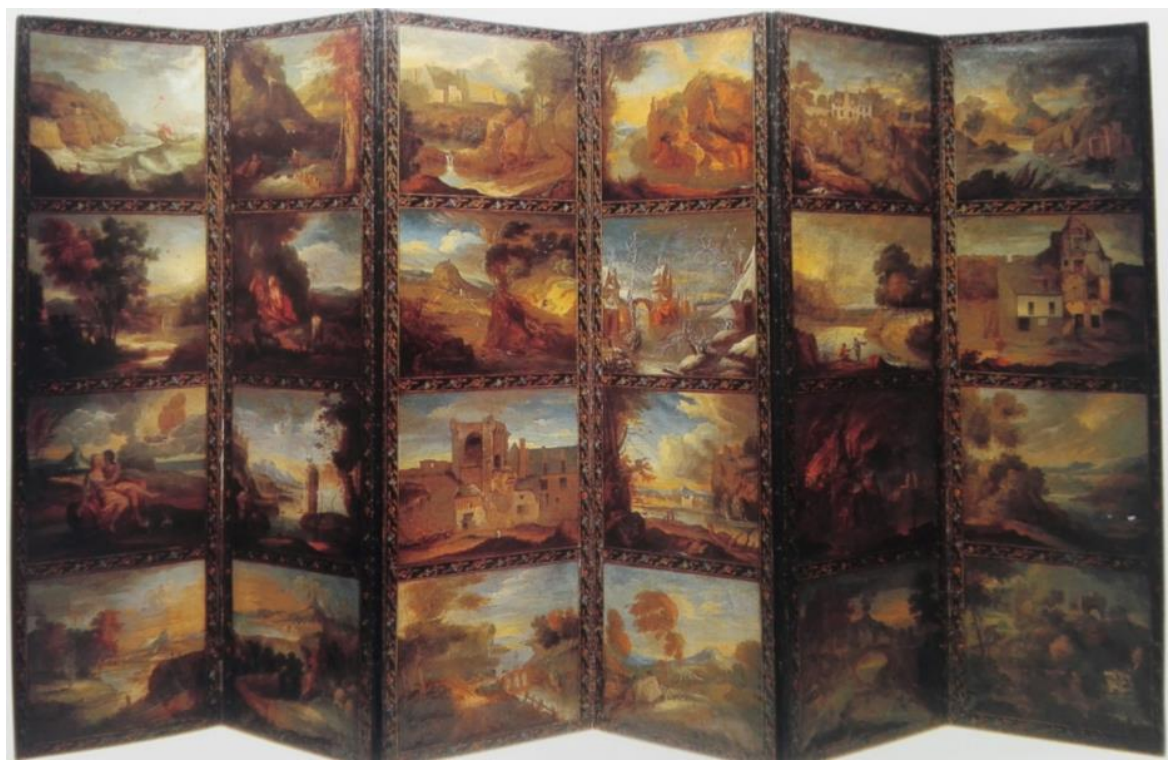

Figura 3. El Gran Tour, Círculo de Alessio de Marchis, primera mitad del siglo XVIII. Biombo de seis hojas, óleo sobre lienzo, 2.13 x $4.16 \mathrm{~m}$.

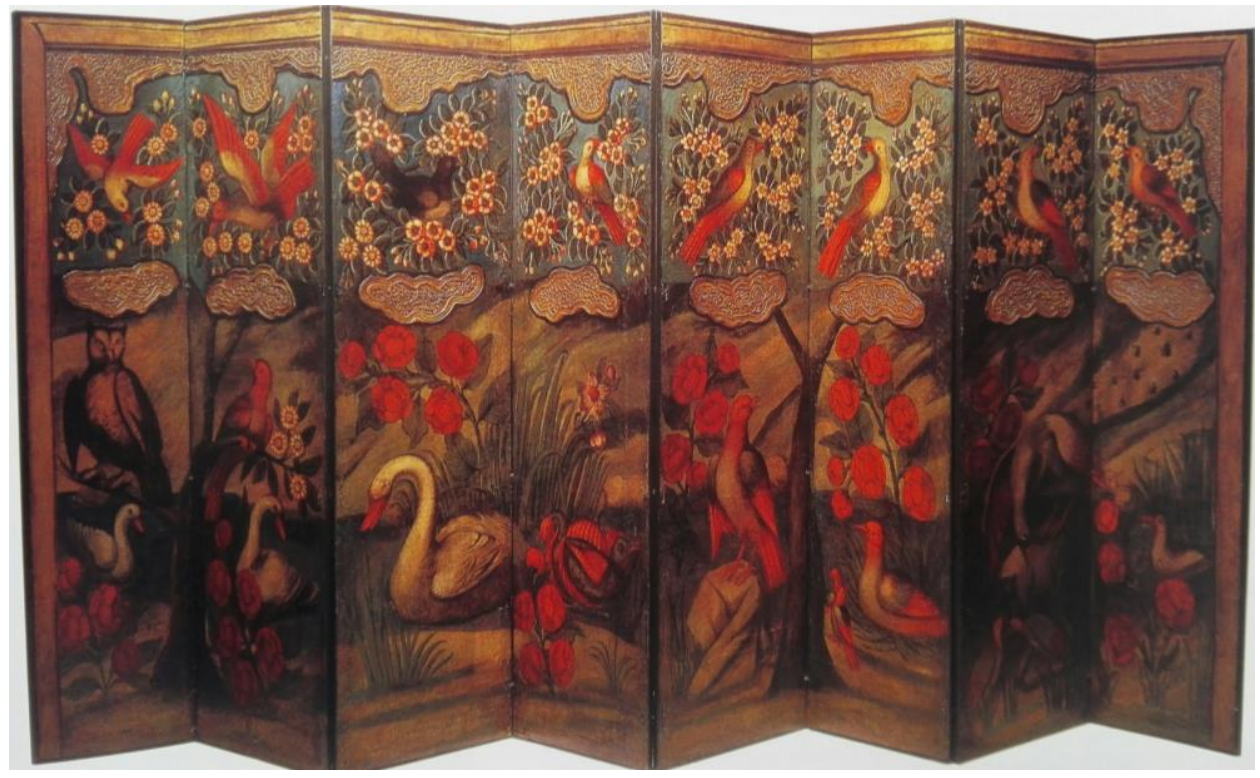

Figura 4. Aves, Escuela mexicana, finales del siglo XVII. Biombo de ocho hojas, óleo sobre lienzo con aplicación de oro sobre base de almagre, 1.96 x 4.50 m. 
En los dos primeros, la representación de la naturaleza es descriptiva, y se construye con el uso de las tradicionales herramientas de la perspectiva (lineal y aérea) y del claroscuro, además de -en el caso del segundo-con el objetivo de ofrecer una narración encadenada. Cuando observamos el tercero, no es difícil adivinar una intención más decorativa en la imagen de la naturaleza que nos propone. En él, los elementos animales y vegetales se repiten rítmicamente, y el uso del color contribuye a acentuar esta sensación de ritmo regular y sistemático, de modo similar a lo que sucede cuando contemplamos un estampado textil, pero sin abandonar la idea del paisaje que se articula por medio de varios planos de profundidad. Lo que tienen en común los tres biombos es una clara vocación paisajística; en ese sentido, se comportan como tradicionales pinturas de paisaje, por más que el soporte pictórico no sea el tradicional o que, en ocasiones, lo decorativo parezca imponerse. Estos paisajes son paisajes, por encima de cualquier otra cosa, y pioneros, así, en la historia del arte novohispano. Para proseguir con nuestra búsqueda más allá del género pictórico endogámico, necesitamos regresar a la pintura de retrato; fundamentalmente, al retrato civil.

\section{El paisaje como atributo del personaje dentro del retrato novohispano}

Para llevar a cabo nuestro análisis intergéneros, clasificaremos los elementos naturales-paisajísticos que pueden encontrarse en el corpus de retratos analizado -citado unos párrafos más abajo- en tres categorías de análisis: 
1. La naturaleza-escenario y su representación realista en el cuadro

2. Los estampados vegetales y paisajísticos de los textiles producidos y/o usados en Nueva España durante el siglo XVIII

3. El jardín como realidad material y como metáfora de las virtudes de la persona.

\section{La naturaleza-escenario y su representación en el cuadro}

En esta primera categoría incluiremos las representaciones de cielos, nubes, árboles y demás elementos de la naturaleza que aparecen en los retratos como fondos de estos, casi siempre del otro lado de una ventana o de un arco, y que en un principio podrían procesarse iconográficamente como elementos secundarios de la composición, al parco servicio de la profundidad espacial en la misma. Estos elementos no cuentan, aparentemente, con una carga de significado que abone a la lectura simbólica y narrativa del cuadro.

Entre los ejemplos que propongo para integrar esta primera categoría están el retrato de la marquesa del Apartado, María Magdalena de Villaurrutia y López Osorio, obra de Miguel de Herrera; el de don Mateo Vicente Musitu y Zalvide y su esposa doña María Gertrudis de Salazar y Duarte, pintado en 1799 por Joseph Mariano; el retrato anónimo de don Fernando de la Campa Cos, primer conde de San Mateo de Valparaíso; el también anónimo retrato de don Miguel de Berrio y Zaldívar, marqués del Jaral de Berrio y conde de San Mateo de Valparaíso; el retrato de la niña Ignacia Dionisia de Ibargoyen y Miguelena, pintado en 1760 por algún integrante de la escuela de Cabrera; y el retrato del virrey duque de Linares, 
de $1714 .{ }^{9}$ En todos ellos, podríamos afirmar con cierta claridad que lo que se nos muestra en el fondo de la composición es un paisaje, aunque sea fragmentado y aunque su presencia sea secundaria, como de telón de fondo; y podríamos dejarlo ahí. Pero si damos por buena la premisa enunciada al principio de estas páginas, que dice que un paisaje es una construcción subjetiva de la naturaleza, y que solo aparece en sociedades con determinadas características, ¿no resultaría cuando menos interesante tratar de averiguar de qué manera esa subjetividad añade narración visual a cada uno de estos retratos?

Analizaré específicamente uno, en el que parecen condensarse algunos de los puntos de la hipótesis que anima esta investigación.

\footnotetext{
9 La selección efectuada para integrar el corpus de esta investigación fue realizada a partir del análisis de las fuentes documentales consultadas; se trata de una primera aproximación, breve, al vastísimo universo del retrato civil novohispano. Se eligieron retratos particular y cualitativamente significativos para nuestro planteamiento de investigación, por la especial presencia en ellos de la naturaleza en sus diferentes modalidades. Las pinturas pertenecen a diferentes colecciones, tanto públicas como privadas. Se incluye un listado de las piezas, con su ficha técnica completa, al final de este texto.
} 


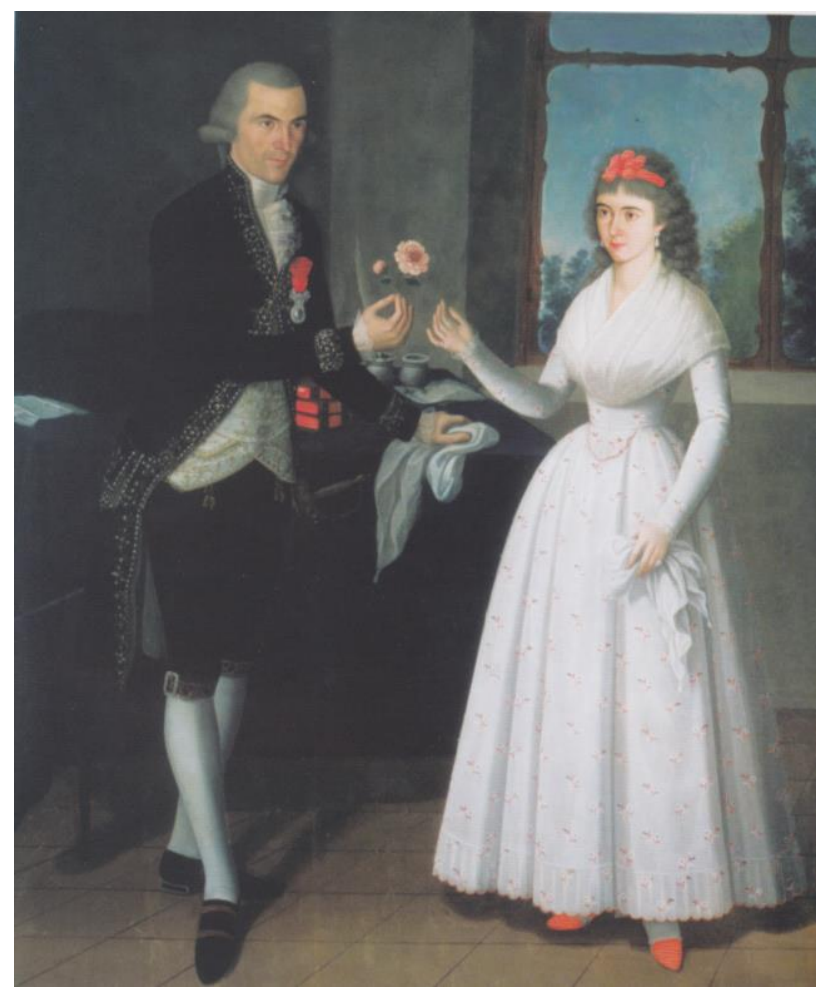

Figura 5. Joseph Mariano, retrato de don Mateo Vicente Musitu y Zalvide y su esposa doña María Gertrudis de Salazar y Duarte, 1799. Óleo sobre tela, 206 x 165 $\mathrm{cm}$. Banco Nacional de México.

El retrato clasicista ${ }^{10}$ de los esposos Musitu y Salazar (figura 5) se revela particularmente interesante porque la realidad natural se nos muestra representada en este de dos maneras, en lo que podríamos identificar como sendos géneros pictóricos -la naturaleza muerta y el paisaje-; pero que yo propongo que se hallan, en este caso, intrínsecamente relacionados. Por un lado, tenemos la flor que el esposo ofrece a su esposa, que resulta fácil de insertar en la tradición pictórica novohispana de la época, tradición que continuaría tanto en la pintura como en la fotografía del México independiente del siglo XIX. El esposo le extiende una flor rosada a su

${ }^{10}$ Nos dice Verónika Volkow (en Martínez y Servín, 2000: 39), en relación con el retrato clasicista, que "Este arte concebido como corrección de la naturaleza no se agota en un afán esteticista, sino que implica una militancia espiritual y moral secreta”. 
cónyuge como una metáfora de ella misma, de su pureza mariana, virginal, de la esencia de su feminidad, la esencia de la mujer virtuosa de su tiempo. Este ${ }^{11}$ es un símbolo, insisto, de muy extensa implantación, que perdurará a través de las décadas y de los regímenes políticos, llegando a traspasar incluso los límites físicos y simbólicos impuestos por las paredes de las cárceles decimonónicas. ${ }^{12} \mathrm{La}$ esposa, sonriente y muy recatada, corresponde al gesto del marido con su mano derecha abierta y dispuesta a recibir el regalo que la espejea. ${ }^{13}$

Al mismo tiempo, justo detrás de ella, enmarcando su cabeza y torso, hay una ventana cerrada, pero sin cortinajes, a través de la cual podemos ver las copas de unos árboles recortadas contra el cielo despejado. El pintor ha tenido mucho cuidado a la hora de decidir la altura de cada árbol, de manera que ninguno de ellos opaca el cabello de la mujer, cuya cabeza contrasta, así, suavemente con el azul pálido del cielo. Resulta, entonces, interesante la escenificación llevada a cabo para identificar a la mujer con la naturaleza, tanto mediante la estrategia del símbolo, como por medio del uso de la última como marco para la primera. En otros retratos en los que se incluye un fondo boscoso esto no es así, y varios, por cierto, no son

\footnotetext{
${ }^{11}$ Es decir, la flor (a punto de ser) sostenida por una mano femenina.

${ }_{12}$ Como lo desarrollan algunos análisis de fotografía carcelaria en el Porfiriato, que demuestran que la flor en la mano fue usada como atributo femenino incluso en ese inhóspito espacio simbólico. Remito al lector a un artículo de mi autoría titulado "En manos del fotógrafo: la construcción de las representaciones de la mujer y de la fachada personal femenina en la fotografía decimonónica mexicana”, aparecido en el número 140 de la revista Relaciones (2014).

13 "El cuadro, al igual que sujeta sus formas al concierto de una composición, enlaza a sus personajes en una filosofía erótica. Reúne colores con armonía, y seres y almas según leyes subyacentes y poderosas. Hay un tratado de amor en este retrato. El juego de brazos y torsos entre el hombre y la mujer dibuja una lemniscata, un infinito circuito de energía. En dos puntos del enlace la circulación se interrumpe, con los pañuelos blancos que sostienen ambos en la mano izquierda y que los unen y separan a la vez, y con la rosa que es casi como una extensión de sus manos, una tercera mano vegetal y exquisita. La rosa es un puente, un broche, y el foco de atención y de intención del cuadro..." (Verónika Volkow, en Martínez y Servín, 2000: 39).
} 
femeninos, sino masculinos. De entre los retratos masculinos nombrados en esta categoría, llama particularmente la atención uno de los más antiguos, el del virrey duque de Linares, por el detalle -no creo que casualde que lo que se ve al otro lado de la ventana del fondo es el cielo nocturno. Este retrato, por cierto, ha sido exhaustivamente analizado por Beatriz Berndt León Mariscal (2011), por si el público lector deseara adentrarse en los secretos simbólicos del mismo.

Este primer uso de la representación de la naturaleza dentro del género del retrato comienza a mostrarnos que, en no pocas ocasiones, la presencia de esta no es trivial o simplemente decorativa, sino que obedece a una estrategia por parte del pintor para construir una narración compleja, por capas, que enriquece la descripción que se hace de los retratados.

La segunda categoría de análisis que propongo tiene que ver con una pieza clave en esas máquinas de significar que son, por un lado, las fachadas personales de la élite novohispana dieciochesca y, por otro, los retratos pictóricos en los que aparecen representadas: los tejidos con los que se visten y los objetos con los que se adornan las personas que los protagonizan, como vemos a continuación.

Los estampados florales y paisajísticos de los textiles producidos y usados durante el siglo XVIII

De los tejidos consumidos en la Nueva España durante los 250 años que discurren entre 1565 y 1815 -fechas entre las que opera la Nao-, una enorme parte provino de territorios de ultramar, concretamente de Asia, y era transportada a bordo de lo que pronto se dio en llamar la Nao de China, Galeón de Manila o Galeón de Acapulco (Ruiz, 2016: 48). Estas embarcaciones cubrían el recorrido transpacífico entre Manila y Acapulco 
en alrededor de cuatro meses; habiendo arribado al puerto novohispano, descargaban sus mercancías para ser distribuidas no solo por Nueva España, sino también por otros territorios de América -sobre todo Perúhasta alcanzar la metrópoli ibérica -esto último a través de la Carrera de Indias, que salía de Veracruz con destino final en Sevilla (Ruiz, 2016: 48).

Con frecuencia se piensa que en la Nao de China se transportaban únicamente artículos, además de exóticos, lujosos y muy caros (Slack, 2012: 107), solo al alcance del capital económico y social de las élites. Esto se debe en parte a que está bien documentado que, para estas últimas, el acceso a ciertos bienes importados del Reino del Medio y otras naciones asiáticas les proporcionó la posibilidad de llevar a cabo lo que Thorstein Veblen denominaría siglos después un consumo ostentoso -conspicuous consumption - 14 casi imprescindible a la hora de reforzar su capital simbólico, fundamentalmente ante sus pares, pero también ante las clases menos favorecidas que la suya. Hablo de los rasos, sedas, satenes y brocados de colores vivos y estampados exóticos, usados tanto en la indumentaria femenina como en la masculina, pero también de abanicos o de diferentes piezas de mobiliario como, por ejemplo, los célebres biombos.

14 En su clásico libro de 1899 titulado Teoría de la clase ociosa, el economista estadounidense Thorstein Veblen (2005) desarrolla conceptos hoy fundamentales para entender el consumo de bienes materiales y simbólicos llevado a cabo por las élites de su tiempo -y relativamente fáciles de extrapolar al contexto actual-, entre los que destacan el consumo ostentoso (conspicuous consumption, consumir para dejar sobradamente demostrado el estatus social y, así, afianzarlo ante los pares y los integrantes de otros grupos sociales), el cual lleva pareja la ostentación general en la exhibición de los productos de ese consumo, o del ocio, como muestra también de dicho estatus; y la emulación, que sería la imitación que los integrantes de las clases subalternas llevan a cabo, en la medida de sus posibilidades, del consumo de las élites, con el fin de mejorar su propio estatus desde la construcción de su imagen ante los demás. Uno de los ejemplos mejor y más profundamente desarrollados por Veblen es el relativo a la indumentaria de las élites occidentales que, en la transición del siglo XIX al XX, resultaba, sobre todo en el caso de las mujeres, particularmente llamativa y costosa y, por lo tanto, era un terreno fértil para el consumo ostentoso. 
Sin embargo, hoy sabemos que estos no fueron los únicos tejidos que llegaban en la Nao. Diferentes variedades de lo que se denominó "mantas", "elefantes" o "quimones" (Martins, 2018: 148)15 llenaron, por ejemplo, el mercado de tejidos de algodón estampado de calidad algo menor que la de los usados por la élite para sus trajes más formales, pero también más económicos. Estos, además, mostraban una interesante mezcla de sensibilidades estéticas y de saberes técnicos desde su origen, la cual ha sido profusamente analizada por la academia, y a la que hoy podemos rastrear, con la necesaria prudencia que impone la esencia de su genealogía, en las pinturas de castas. ${ }^{16}$

Aquí hablaremos únicamente de los artículos de lujo, pues son los que encontramos en prácticamente la totalidad de los retratos elitistas novohispanos dieciochescos revisados. Como decía arriba, estos tejidos formaron parte imprescindible del aparato de ostentación de las élites, por su precio, por su origen, por su riqueza estética; y lo hicieron, además, de un modo idiosincrático. Sabemos que en el mismo periodo llegaron a Europa y a sus cortes reales tejidos similares, que fueron también objeto de adoración y de uso por parte de las respectivas élites. Sin embargo, la particularidad novohispana reside en su concepto de otredad a la hora de

\footnotetext{
15 En Nueva España, por ejemplo, la palabra quimón, aunque con variadas acepciones, se refirió, en el terreno de los textiles listos para su uso en sastrería, a "un tejido de algodón muy fino, pintado y estampado" (con motivos florales grandes o pequeños), "del tamaño de ocho varas" y de origen asiático, que con frecuencia se usó en la elaboración de indumentaria tanto femenina como masculina (en casacas, enaguas y basquiñas, por citar algunas).

${ }^{16}$ Cuando analizamos con detenimiento estas series de pinturas, se puede comprender que muchas son copias de otras anteriores, no representaciones directas de los modelos que aparecen sobre el lienzo o de sus vestimentas. Los sucesivos $-\mathrm{y}$ muchas veces involuntarios, así como apenas perceptibles-cambios que se van dando en las prendas de vestir, así como la idealización o fantasía que el pintor de la pieza original pudo imprimir en ella, vuelven problemático el uso de las pinturas de castas como fuente confiable para la historia de la indumentaria en México. Al respecto se recomienda revisar el exhaustivo texto de Ilona Katzew (2004), La pintura de castas.
} 
recibir y asimilar algo tan cotidiano y cercano como los tejidos con los que vestirse, al punto de que podría hablarse de una chinería rococó europea y, como contraparte, una mezcla novohispana. O, dicho de otro modo, tal y como Edward R. Slack (2012: 125) apunta:

la visión europea de la otredad asiática como no solo remota, extranjera y exótica, sino también cultural y tecnológicamente inferior, no coincide con la novohispana. Aquí, la mezcla de culturas y tradiciones, y el deseo de aceptar o al menos tolerar a la población asiática y sus productos, generan un proceso de orientalización que contrasta con el equivalente en la Europa del mismo periodo histórico. ${ }^{17}$

Mi propuesta es que esa diferente visión de lo asiático se puede encontrar también en el modo en el que la naturaleza domesticada que aparece en tejidos y abanicos es utilizada por la élite novohispana a la hora de vestirse. Estos tejidos, además, no siempre llegaron ya estampados. Hoy sabemos que una buena parte de los textiles de seda consumidos en Nueva España durante el siglo XVIII se tejía aquí, pero con hilo llegado en la Nao desde China, más económico y fácil de manipular (Bonialian, 2016: 153). Una vez en territorio novohispano, la norma era imitar, con adaptaciones, los exóticos estampados vegetales y animales chinos, o japoneses, o de la India, en un ejercicio de apropiación que espero sea analizado convenientemente por la academia, pues ahí reside uno de los ingredientes fundamentales de la idiosincrasia estética novohispana en el terreno vestimentario.

17 [Moreover, the Eurocentric sense of 'otherness' for Asia that is expressed as cultural or technological inferiority and foreign/exotic/remote populations and lands, is, for the most part, nonexistent in the history of New Spain. To the contrary, the blending of cultures and traditions, a willing acceptance or tolerance of Asian people and products that constituted the process of Orientalization in colonial Mexico stands in stark contrast to the historical experiences of European nations during the same time frame.] 
El "producto final" que contemplamos en estas páginas que nos ocupan es un festival visual construido en torno a la naturaleza y a sus estaciones. En este caso no quiero ceñirme a un solo retrato, porque considero mucho más importante analizar la sensación de conjunto, de familia estética que nos dejan todos, como grupo. El paisaje heterodoxo que contemplamos en los vestidos, las chupas, los chalecos y las sayas, así como en los abanicos y en los tocados florales, es vibrante y colorido, y apenas deja espacio para descansar la vista. Llama particularmente la atención la indumentaria masculina (figura 6) y la infantil (figura 7), donde encontramos una abundancia de motivos florales de tamaño considerable, nada habituales en sus paralelos europeos, y que en el caso de las niñas llegan a crear una notoria desproporción entre el tamaño del estampado y el de su portadora. En algunos vestidos de mujer podemos observar paisajes completos, bordados (figura 8); en otros, reproducciones de mundos claramente asiáticos, con pagodas, animales fantásticos y plantas de todos los colores (figura 9). ${ }^{18}$ No extraña entonces que, en mitad de este panorama, las monjas coronadas no resalten por su extravagancia, sino que, al contrario, se terminen mimetizando tanto con la tradición barroca novohispana de las ornamentaciones florales y fantásticas como con el ambiente estético general de los retratos de la élite.

\footnotetext{
${ }^{18}$ La mayor parte de las prendas que compusieron la indumentaria de los personajes retratados, sobre todo en el caso de los infantes, se usaba fundamentalmente en ocasiones especiales, aquellas investidas con un alto grado de formalidad y/o de exposición al escrutinio público, aquellas donde la máscara/fachada personal jugaba un papel más crítico en la construcción de la persona dieciochesca novohispana. En este sentido, un retrato es el dispositivo definitivo de exposición, pues se pinta con la vocación de representar al retratado, ante los demás y para la posteridad, en su punto máximo de exhibición ante sus pares, y eso por sí solo justifica la elección de un determinado vestuario.
} 


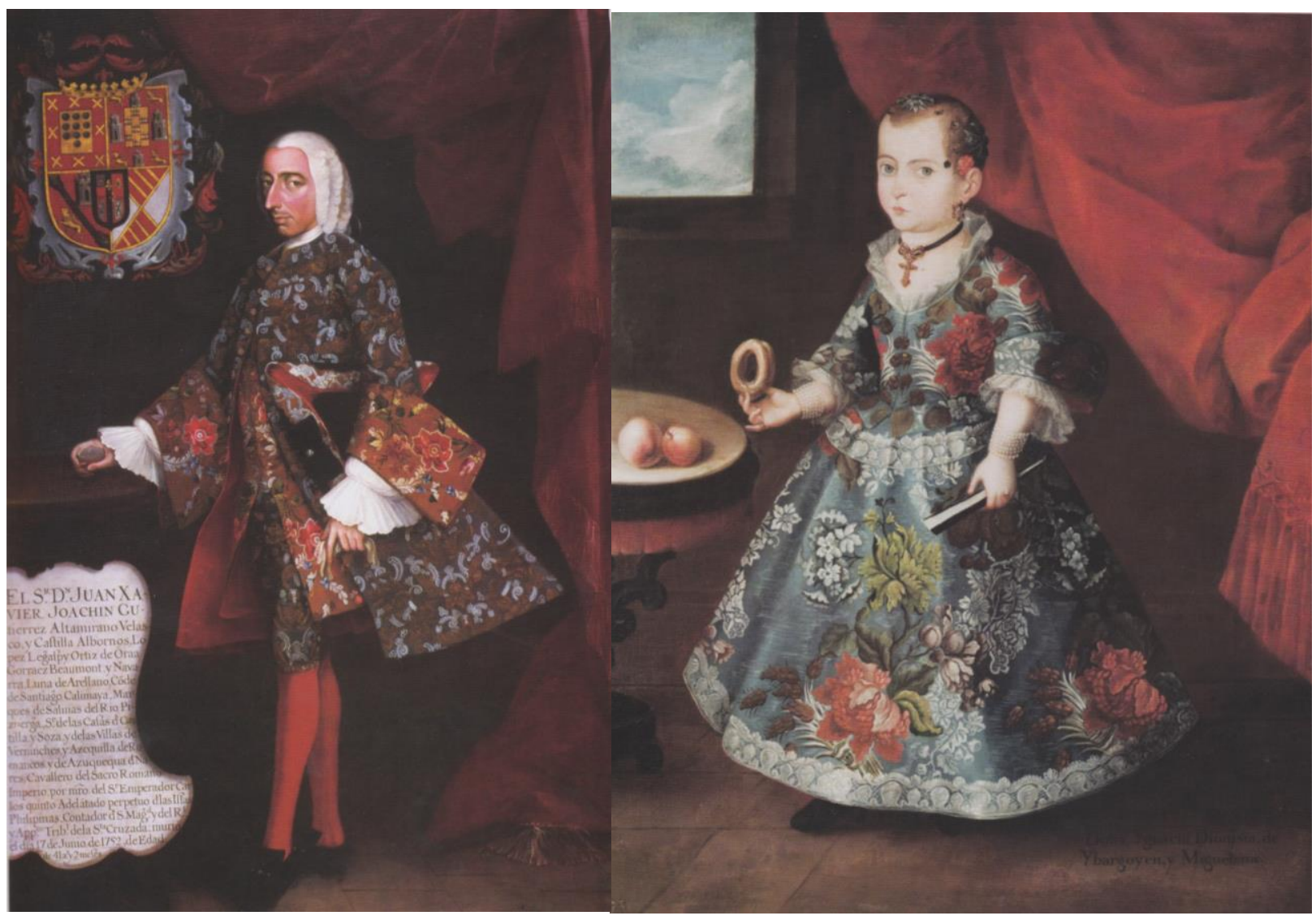

Figuras 6 y 7. Miguel Cabrera, retrato de Juan Xavier Joaquín Gutiérrez Altamirano, séptimo conde de Santiago de Calimaya, 1752. Óleo sobre lienzo, 207.31 x $136 \mathrm{~cm}$. Brooklyn Museum; Escuela de Cabrera, retrato de la niña Ignacia Dionisia de Ibargoyen y Miguelena, 1760. Óleo sobre tela, 102 x $79 \mathrm{~cm}$. Museo Nacional de Historia. 


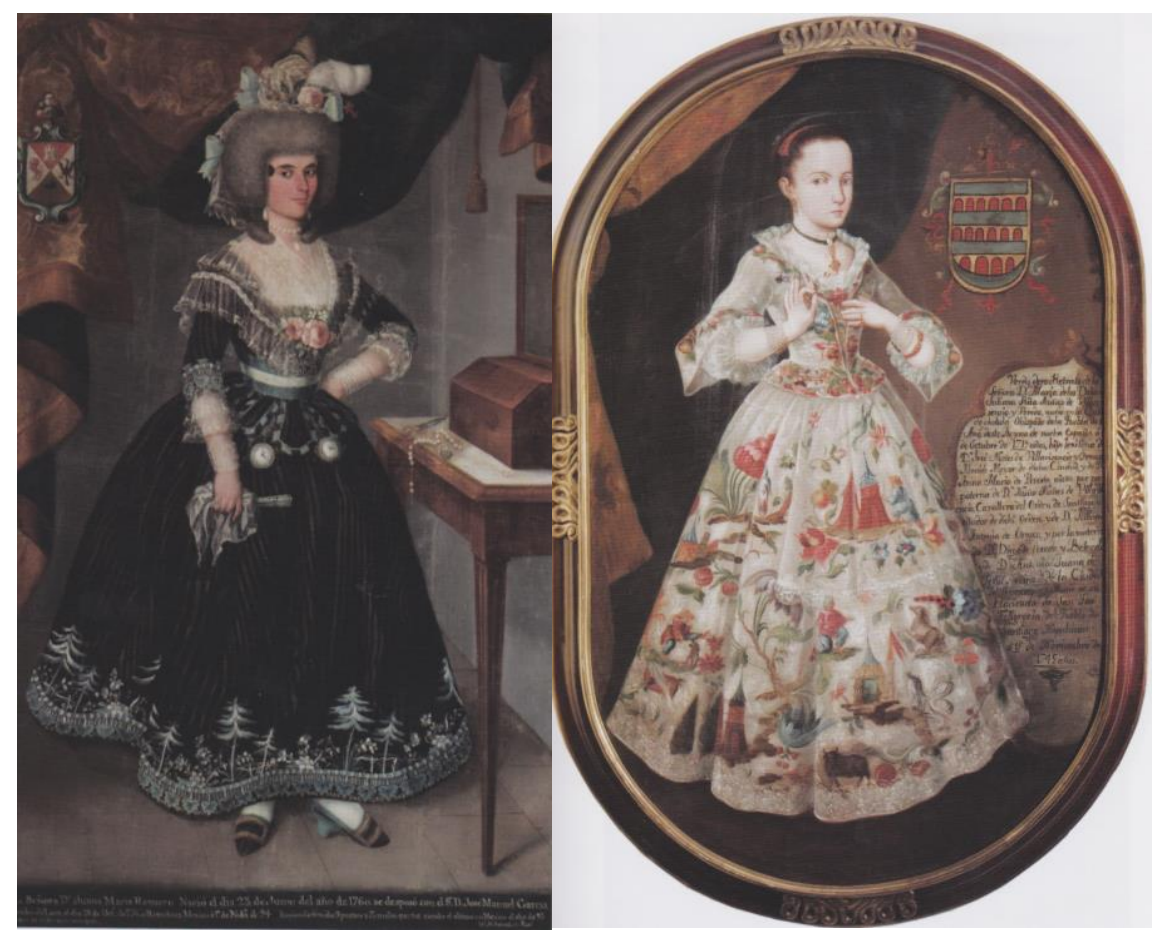

Figuras 8 y 9. Ignacio María Barreda, retrato de Juana María Romero, 1794. Óleo sobre lienzo, 190 x $116 \mathrm{~cm}$. Museo Nacional de Historia; Anónimo, retrato de María Juliana Rita Núñez de Villavicencio y Peredo, ca. 1733. Óleo sobre lienzo, 172 x $109 \mathrm{~cm}$. Colección particular.

Finalmente, y en lo que yo creo que conforma, tal y como ya se dijo, el epítome de la naturaleza domesticada en la pintura novohispana dieciochesca, tenemos nuestra tercera categoría de análisis.

El jardín como realidad material y como metáfora de la persona

Prácticamente cada civilización ha tenido un concepto propio de jardín. Este metapaisaje, que, en palabras de Ana Luengo, supone la representación, “en un espacio y un tiempo delimitados, de los ideales y 
aspiraciones del hombre" (Luengo, en Maderuelo, 2009: 129), ha ido cambiando de imagen en cada momento y lugar, llegando a funcionar como reflejo de "la estructura espiritual básica de cada sociedad y cada cultura" (Luengo, en Maderuelo, 2009: 129). El jardín mimetiza la estructura de la naturaleza y, al mismo tiempo, se diferencia oportunistamente de ella; por lo tanto, supone la domesticación definitiva de la misma. No hay más que comparar un jardín japonés zen con uno inglés para, por otro lado, observar cómo esta domesticación se sitúa histórica y culturalmente. Resulta lógico pensar entonces que, si un jardín es utilizado como fondo para la construcción del espacio en el que se nos presenta al personaje retratado, este jardín pueda tener algo que decir sobre dicho personaje.

En los retratos que componen el incipiente corpus de esta investigación aparecen representados jardines, con claridad y compleción, en dos ocasiones. Una de ellas es el retrato de María Luisa Gonzaga Foncerrada y Navarrieta, pintado por José María Vázquez en 1806 (figura 10), y otra es el ya referido de la señora Ramona Musitu y sus dos hijas (figura 1). En ambos casos, lo que se aprecia en el fondo de la composición son sendos jardines de estilo francés, desarrollados durante el periodo barroco y exportados a multitud de naciones -al igual que la moda-a partir de ese momento. España y sus colonias de ultramar no fueron una excepción, de modo que hasta Nueva España llegó esta particular manera de ordenar la naturaleza: con caminos simétricos y ligeramente ondulantes -que estructuran el espacio horizontal y dirigen los pasos de los visitantes, jalonados estratégicamente con fuentes monumentales y árboles de tronco largo debidamente podados, combinados con parterres adornados con flores, y sin asomo alguno de la chinoiserie, muy presente en los jardines de otras naciones, como la inglesa, por ejemplo (Soto Caba, en Buttlar, 1993: 279). Y, además, cercanos a la casa, lo cual justifica, en los ejemplos que nos 
ocupan, que puedan verse al fondo de la escena, lo que los convierte, más que en un mero marco estético de la misma -y aquí presento mi teoría al respecto-, en un atributo monumental, tridimensional y lleno de posibilidades semánticas.

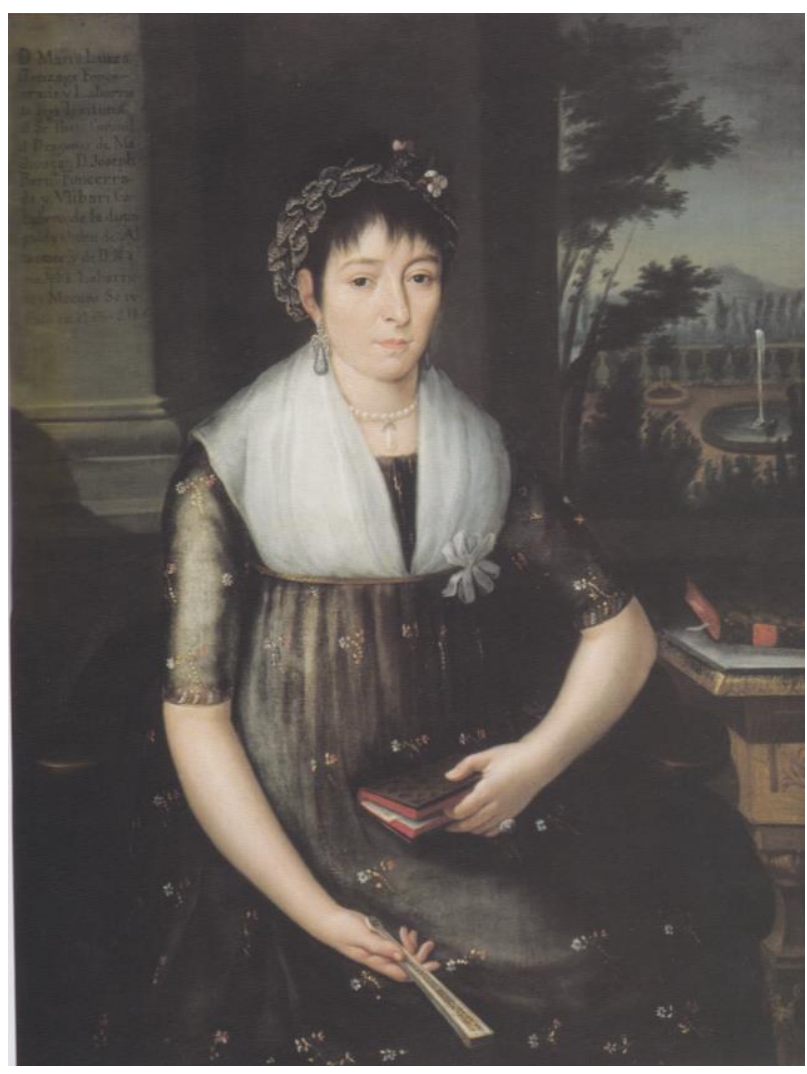

Figura 10. José María Vázquez, retrato de María Luisa Gonzaga Foncerrada y Lavarrieta, 1806. Óleo sobre tela, 104 x $81 \mathrm{~cm}$. Museo Nacional de Arte.

Analizaremos a continuación el segundo ejemplo de los dos citados, a la sazón el mismo con el que empezamos nuestras reflexiones. Para hacer honor a la simetría de un jardín barroco, vamos a terminar, entonces, nuestras consideraciones con él. 


\section{En conclusión. El paisaje en retrato}

Ramona Antonia Musitu y Zalvide-Goitia y sus dos hijas aparecen retratadas, en el año de 1793, a punto de adentrarse en un jardín de estilo francés, ordenado y al mismo tiempo orgánico y ondulante, en el que puede adivinarse una estructura de caminos simétricos -que sirve para poner orden al arbolado, a los parterres y a las jardineras con flores-y tres fuentes, la más cercana a nosotros decorada con una monumental representación de Neptuno, un antiguo y clásico dios de ultramar. El jardín se separa del mundo exterior por medio de muros sólidos y altos, con arcadas que permiten ver el paisaje lejano, salvaje y montañoso, y a los cuales, por su cara interior, se arriman unos estilizados y bien podados cipreses. Estos remedan la proporción espigada de los arcos, al mismo tiempo que contrastan con el arbolado sin podar que puede verse al otro lado de estos.
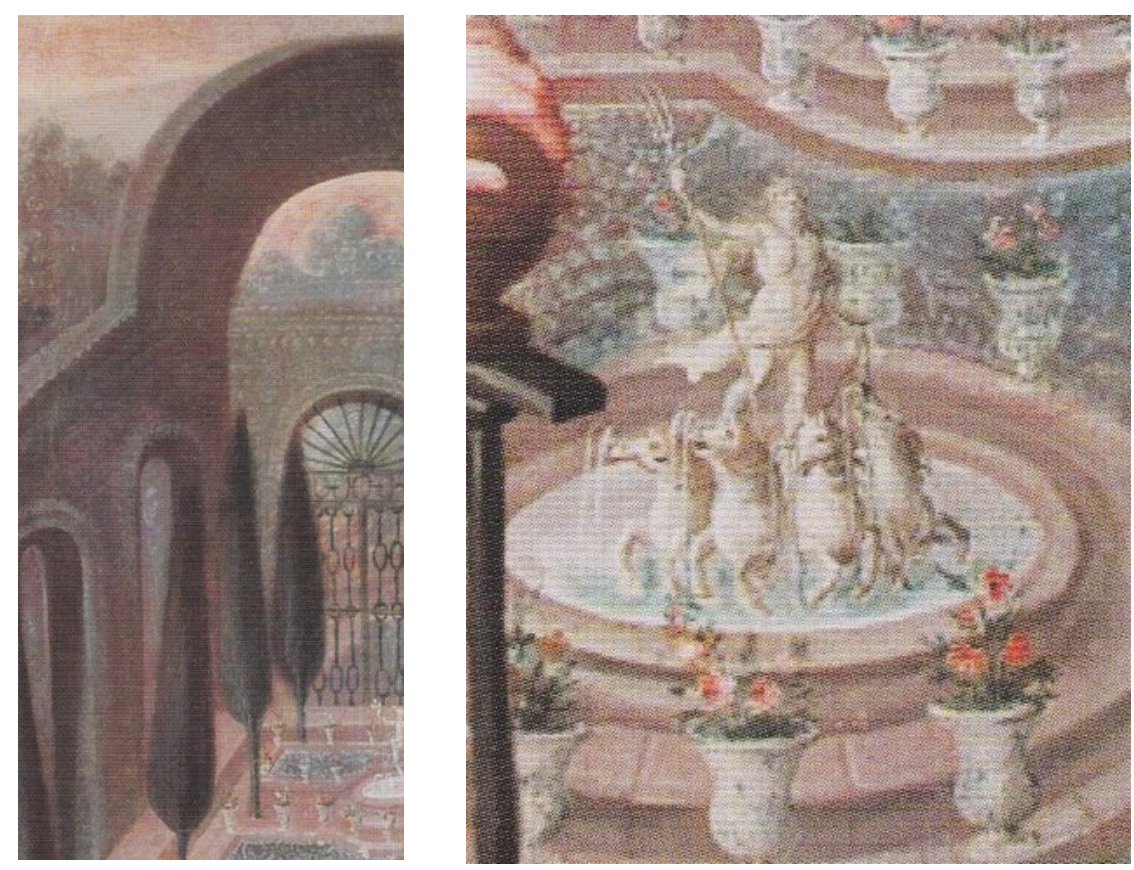

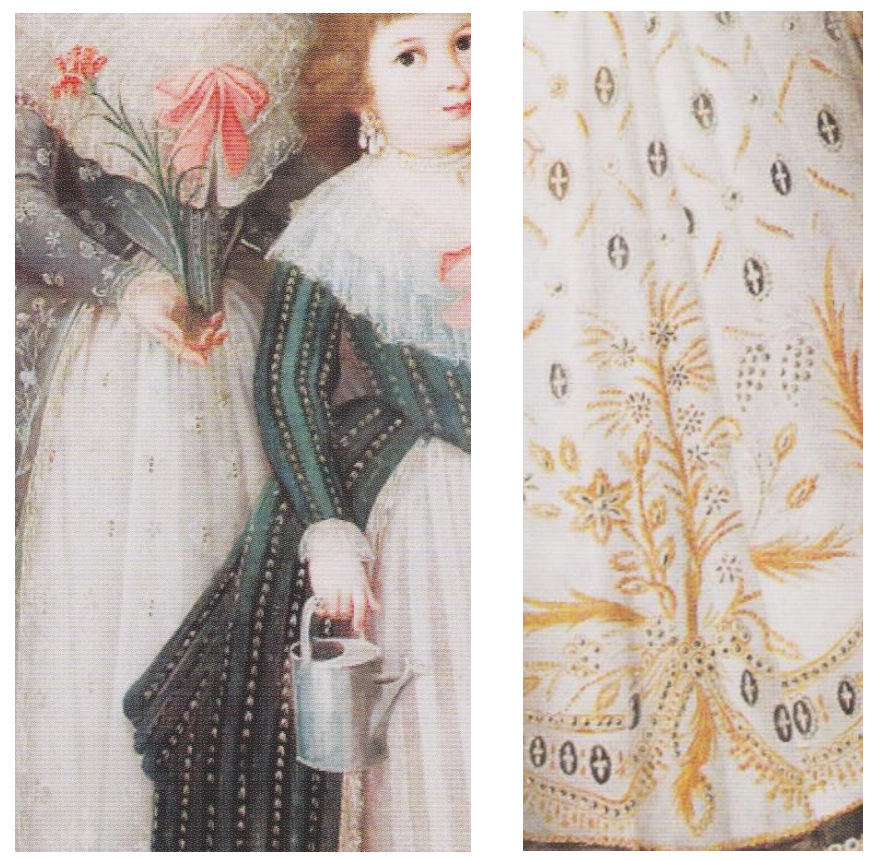

Figura 11. Detalles a, b, c y d de la figura 1.

Ramona y sus hijas, por su parte, parecen dispuestas a integrarse en el orden, la armonía y la civilización exhibidos por este jardín, y a cuidar de él, puesto que cargan bulbos ya florecientes y una pequeña regadera, que las hacen ver como jardineras, como ordenadoras en potencia de la naturaleza.

Sus ricas y delicadas ropas -tres robes á l'inglese ${ }^{19}$ bordados a mano, pudorosamente combinados con otros tantos fichús de fina gasa y encaje para cubrir sus hombros y parte de sus cuellos-, así como los complementos que las aderezan -aretes, tocados, pelucas, moños...-, a la

\footnotetext{
${ }^{19}$ El vestido a la inglesa rococó, siendo una invención francesa, hizo honor al interés que despertaban en el país galo ciertas costumbres británicas, como la de portar una indumentaria sencilla y desprovista de ahuecadores aparatosos para las faldas como el célebre panier francés, que resultaba, en esas mismas décadas, imprescindible para dar la forma y el volumen requeridos en el vestido más popular del momento entre las mujeres de las élites occidentales dieciochescas: el robe á la française o vestido a la francesa (Cosgrave, 2006: 174).
} 
vez que hablan de su clase social desde lo económico, hacen eco de la cualidad civilizada y civilizatoria del paisaje domesticado en el que habitan: el bouquet floral del sombrero de Ramona, o el estampado y bordado vegetales de dos de los tres vestidos, no solo vinculan a las retratadas con lugares remotos en los que fueron producidas las materias exóticas y ostentosas con las que día a día ellas construyen su capital simbólico y social, sino que también lo hacen con un concepto de naturaleza que las sitúa, según el pensamiento de las élites de su tiempo, en un lugar espiritual de privilegio, más allá del "salvajismo" y del desorden de la naturaleza virgen que aún no ha sido dominada por el ser humano.

El paisaje en su retrato, entonces, se convierte en algo más que un elemento decorativo o trivial.

El paisaje y su naturaleza domesticada, esas invenciones humanas, construyen, sitúan, señalan y, finalmente, completan como personas a Ramona Antonia y a sus hijas, en el esplendor del siglo XVIII novohispano, fungiendo como ejemplo vibrante, aún hoy, de que los mensajes de una obra pictórica de esta envergadura siempre son múltiples y complejos, y se elaboran y organizan por capas. Lo que observamos al sumergirnos en un cuadro como este es, finalmente, un conjunto de dimensiones de representación simbólica entrelazadas, de las que la simbiosis que representa el "paisaje en retrato", como hemos querido llamar aquí a esta particular forma de hibridar un género pictórico con otro, constituye, a nuestros ojos, un ejemplo efectivo y lleno de poesía.

\section{Referencias}

AA. VV. (1994). Artes de México. El retrato novohispano. 25, disponible en: https://www.jstor.org/stable/i24320048. 
ALFARO, A. (1994). "Espejos de sombras quietas", Artes de México. 25 (nueva época), 9-23.

BASTARRICA, B. (2014). "En manos del fotógrafo: la construcción de las representaciones de la mujer y de la fachada personal femenina en la fotografía decimonónica mexicana”, Relaciones. 35 (140), 43-69.

BERNDT MARISCAL, Beatriz (2011). "Todo emana de su persona, a imagen del soberano: reflexiones a partir de un retrato del virrey duque de Linares”, Anales del Instituto de Investigaciones Estéticas. 33 (99).

BONIALIAN, Mariano (2016). "La seda china en Nueva España a principios del siglo XVII. Una mirada imperial en el memorial de Horacio Levanto", Revista de Historia Económica-Journal of Iberian and Latin American Economic History. 35 (1), 147-171.

BUTTLAR, Adrian von (1993). Jardines del clasicismo y el romanticismo. El jardín paisajista. Madrid: Nerea.

CORTINA, Leonor (1994). "El gesto y la apariencia”, Artes de México. 25 (nueva época), 38-45.

COSGRAVE, Bronwyn (2006). Historia de la moda. Desde Egipto hasta nuestros días. Barcelona: Gustavo Gili.

COSGROVE, Denis (2002). "Observando la naturaleza: el paisaje y el sentido de la vista", Boletín de la Asociación de Geógrafos Españoles. 34, 63-89.

CURIEL, Gustavo (1999). "Los biombos novohispanos: escenografías de poder y transculturación en el ámbito hispánico" (9-32), Viento detenido: mitologías e historias en el arte del biombo. México: Asociación Carso/Museo Soumaya.

GOFFMAN, Erving (1997). La presentación de la persona en la vida cotidiana. Buenos Aires: Amorrortu. 
KATZEW, Ilona (2004). La pintura de castas: representaciones raciales en el México del siglo XVIII. México: Conaculta.

MADERUELO, Javier (2007). Paisaje y arte. Madrid: Abada.

MADERUELO, Javier (2009). Paisaje e historia. Madrid: Abada.

MARTIN, Richard y Harold Koda (1994). Orientalisms. Visions of the East in Western Dress. Nueva York: The Metropolitan Museum of Art.

MARTÍNEZ, Regina y Nora Angélica Servín (coords.) (2000). Lazos de sangre. Retrato mexicano de familia, siglos XVIII y XIX. México: Gobierno del Distrito Federal.

MARTINS, Andreia (2018). "No hay historia global sin el Pacífico y América: el quimón en Nueva España y la circulación de tejidos de algodón pintado (siglos XVI-XIX)", Revista Complutense de Historia de América. 44, 143-165.

MENA, Enrique (2015). "Una óptica pictórica al paisaje", Revista de Ciencias de la Información. Año XXXII (32), 10-25.

NÚÑEZ MÉNDEZ, Elsaris (2016). "Representando a la mujer de la élite: el diálogo entre el retrato y la pintura de género en los interiores domésticos novohispanos", Kaypunku. 3 (2), 15-55.

PÉREZ VEJO, Tomás y Marta Yolanda Quezada (2009). De novohispanos a mexicanos. Retratos e identidad colectiva en una sociedad en transición. México: Instituto Nacional de Antropología e Historia.

RODRÍGUEZ BOTE, María Teresa (2014). "La visión estética del paisaje en la Baja Edad Media”, Medievalismo. 24, 371-397.

RUIZ GUTIÉRREZ, Ana (2016). “A través del Galeón de Manila: intercambio artístico entre Japón y Nueva España”, 京都外国語大学 ラテンアメリカ研究所 [Boletín del Instituto de Estudios Latinoamericanos de la Universidad de Estudios Extranjeros de Kyoto]. 16, 47-74. 
SANCHIZ, Javier, Víctor Gayol y Academia Mexicana de la Genealogía y Heráldica (s.f.), Ramona Antonia Musitu Zalvide-Goitia, disponible en:

https://gw.geneanet.org/sanchiz?lang=es\&n=musitu+zalvide+goiti $\mathrm{a} \& \mathrm{oc}=\mathrm{o} \& \mathrm{p}=$ ramona + antonia.

SLACK, Jr., Edward R. (2012). "Orientalizing New Spain: Perspectives on Asian Influence in Colonial Mexico", Análisis. Año 15, 43.

VEBLEN, Thorstein (2005). Teoría de la clase ociosa. México: Fondo de Cultura Económica. 